\title{
Economic and Environmental Evaluation and Optimal Ratio of Natural and Recycled Aggregate Production
}

\author{
Milad Ghanbari, ${ }^{1}$ Armin Monir Abbasi, ${ }^{2}$ and Mehdi Ravanshadnia ${ }^{1}$ \\ ${ }^{1}$ Department of Construction Engineering and Management, Science and Research Branch, Islamic Azad University, Tehran, Iran \\ ${ }^{2}$ Department of Civil Engineering, Payame Noor University, Tehran, Iran \\ Correspondence should be addressed to Armin Monir Abbasi; MonirAbbasi@pnu.ac.ir
}

Received 1 June 2017; Revised 15 July 2017; Accepted 14 August 2017; Published 28 September 2017

Academic Editor: Belal F. Yousif

Copyright (c) 2017 Milad Ghanbari et al. This is an open access article distributed under the Creative Commons Attribution License, which permits unrestricted use, distribution, and reproduction in any medium, provided the original work is properly cited.

\begin{abstract}
Steady increase in overexploitation of stone quarries, generation of construction and demolition waste, and costs of preparing extra landfill space have become environmental and waste management challenges in metropolises. In this paper, aggregate production is studied in two scenarios: scenario 1 representing the production of natural aggregates (NA) and scenario 2 representing the production of recycled aggregates (RA). This study consists of two parts. In the first part, the objective is the environmental assessment (energy consumption and $\mathrm{CO}_{2}$ emission) and economic (cost) evaluation of these two scenarios, which is pursued by life-cycle assessment (LCA) method. In the second part, the results of the first part are used to estimate the optimal combination of production of NA and RA and thereby find an optimal solution (scenario) for a more eco-friendly aggregate production. The defined formulas and relationship are used to develop a model. The results of model validation show that the optimal ratio, in optimal scenario, is $50 \%$. The results show that, compared to scenario 1 , optimal scenario improves the energy consumption, $\mathrm{CO}_{2}$ emissions, and production cost by, respectively, 30\%, 36\%, and 31\%, which demonstrate the effectiveness of this optimization.
\end{abstract}

\section{Introduction}

It has been reported that a developed country like Australia produces 8.7 million tons of waste demolition concrete, 1.3 million tons of waste brick, 3.3 million tons of waste excavation rock, 1 million tons of waste glass, and 1.2 million tons of waste asphalt every year [1]. According to other statistics [2], $42 \%$ of all wastes in Australia are related to construction and demolition (C\&D) waste, and of this amount $81 \%$ is waste concrete. Similarly, $29 \%$ of solid waste produced in the United States is C\&D waste [2], and the amount of waste concrete discarded in this country is about 30 million tons per year [3]. It is notable that demand for materials and waste generation both have a direct relationship with the population growth and urbanization [4]. In Hong Kong, 38\% (14 million tons) of waste produced annually is C\&D waste, and of this amount, 11 million tons are reused in state-funded repair, reconstruction, and earthwork operations, and the remaining 3 million tons are disposed in landfills [2]. Japan is far more environmentally friendly in this respect, as only $16 \%$ (750 thousand tons) of its waste generation is related to C\&D (efficient reuse of materials prevents disposal in landfills) [2].

Another notable aspect of this discussion is the overexploitation of aggregate quarries. This overexploitation is undesirable not only environmentally but also from the perspective of sustainable development, because it turns the aggregate resources needed by future generations to C\&D wastes. In the United States, annual production of aggregate is about 2 billion tons and is expected to reach 2.5 billion tons by 2020 [2-5]. Overall, the amount of raw materials consumed globally every year to produce construction materials reaches about three billion tons [6]. From the environmental sustainability perspective, industrial sector is one of the primary sources of air pollution and accounts for 30 to 70 percent of global energy consumption and $\mathrm{CO}_{2}$ emissions [7]. Furthermore, about 80 percent of global greenhouse gas (GHG) emissions are the result of energy production [8].

Recycling of aggregates could serve as a solution to reduce not only the overexploitation of quarries but also the consequent energy consumption and GHG emissions, especially $\mathrm{CO}_{2}$, in the associated industrial operations. In 
addition to economic benefits [9] and environmental merits [10], this solution has technical justification [9-11] as the product can be used confidently in concrete production [11] and road building applications [10]. According to research, the primary factors undermining the prospect of further use of recycled aggregates (RA) are the poor quality of recycling process $[12,13]$ and the poor quality of resulting concrete [14], but according to experimental studies [3, 15, 16], the concrete to be made with RA can be strengthened by proper adjustment of mix design and production process. Utilizing of construction waste powder as cementitious materials in concrete is another application of C\&D wastes $[17,18]$. According to another study, a closed circuit recycling plant outperforms its open-circuit counterpart in this respect [12]. Location of C\&D waste landfill and recycling plants by GISbased methods [19] and evaluation of recycling potential [20] are other research avenues associated with this topic.

Today, life-cycle assessment (LCA) and environmental analysis of construction materials [21] are a primary line of recycling research in Europe. According to research, among all environmental consequences of production of concrete, asphalt, and their constituent materials, $\mathrm{CO}_{2}$ emission has attracted most of the attention [22]. Another recent effort in this field is the reduction of $\mathrm{CO}_{2}$ emission by the use of recycled materials in cement industry in Japan [7]. Studies suggest that energy consumption and $\mathrm{CO}_{2}$ emission can serve as proper evaluation criteria for environmental impacts of concrete waste [14].

Thus far, numerous research projects have been performed on road and building construction to determine the water-to-cement ratio (for concrete mix) and the optimum percentage of bitumen (for asphalt mix). These studies have led to developing several codes and standards in countries. However, little attention has been paid to recycled aggregates. Investigating the environmental potential of the combination of natural and recycled aggregates, this study could act as a minimum effort to encourage the standards' officials to pay attention to the combination of NA and RA aggregates. Indeed, this research assesses the environmental and economic feasibility studies of setting up the recycling centers of aggregates in the landfill location of cities where landfills have created the environmental crisis. It is worth noting that the optimum location of the landfill and recycling plant requires the GIS and optimization studies, which is not in the scope of this research. All of the above-mentioned cases show the gaps in the research into aggregates, which this study aims to cover.

In the present study, mathematical modeling is carried out with two objectives. The first objective is the economic (cost) and the environmental (energy consumption and $\mathrm{CO}_{2}$ emission) assessment of production and recycling of aggregates, which is pursued via a simplified life-cycle assessment methodology. The second objective is to estimate the optimal ratio of production of natural and recycled aggregates based on economic and environmental criteria. For this purpose, the production scenarios of natural and recycled aggregates as well as the hybrid optimal scenario are evaluated and compared.

\section{Methodology and Materials}

Life-cycle assessment (LCA) is an efficient method for evaluating the performance of a product during its lifetime. Research has shown that this approach can be easily adopted for materials such as concrete [23,24]. Another merit of this method is its utility in evaluation of building [25-30] and road construction [31] applications. In view of these merits, this study uses LCA for evaluation of energy consumption, $\mathrm{CO}_{2}$ emission, and the costs associated with aggregate production and recycling. The term aggregate refers to naturally or artificially crushed rock typically used, depending on the size, in the construction of roads and buildings. Technical specifications of aggregates to be used for concrete are specified by different standards such as ASTM C 33 (ASTM C 33M: 2013, Standard Specification for Concrete Aggregates). The major applications of aggregates are in the construction of roads and pavements (bass, subbase, and asphalt) [10, 32] and buildings (structure and envelope), landscaping, and construction of precast concrete pieces [11].

According to the ISO 14040 [33] standard, a LCA should be carried out in four distinct phases that consist of (a) goal and scope, (b) life-cycle inventory, (c) life-cycle impact assessment, and (d) interpretation. This sequence is used in the implementation process of the LCA, which is followed.

2.1. Goal, Boundary, and Inventory Modeling. Aggregates are divided into two types: natural and recycled. Virgin or natural aggregate (NA) refers to the products that are mined by blasting or excavation and then crushed and processed in a crushing plant [34]. Recycled aggregates however are those that are obtained from a recycling plant set-up in a landfill. Both of these plants can be either central (fixed) or mobile [9], but this study is focused on the plants of central type. The functional unit in this study is annual production of NA and/or RA by 480,000 tons/year.

Cradle-to-grave life-cycle of aggregates is illustrated in Figure 1. Cradle-to-gate is the whole phases of Figure 1 except concrete/asphalt plant and construction site/road. As other phases are similar and same for the natural and recycled aggregate, they have not been evaluated. On the other hand, cradle-to-gate assessments are sometimes the basis for environmental product declarations (EPD) termed business-tobusiness EDPs. Thus, cradle-to-gate is chosen in the present research. Based on the cradle-to-gate life-cycle of aggregates, scope and inventory of LCA model can be defined as shown in Figure 2. In other words, Figure 2 serves as the conceptual model of this study. The scope of this study includes natural and recycled aggregates, cost, energy consumption, $\mathrm{CO}_{2}$ emission, and natural and recycled aggregate production plants.

In the inventory of LCA model of this study, the inputs include the aggregate production and recycling processes, the number, type and specifications of machinery, and the cost, energy consumption, and $\mathrm{CO}_{2}$ emission of each piece of equipment, and the outputs are the total amounts of $\mathrm{CO}_{2}$ emission, energy consumption, and cost. 


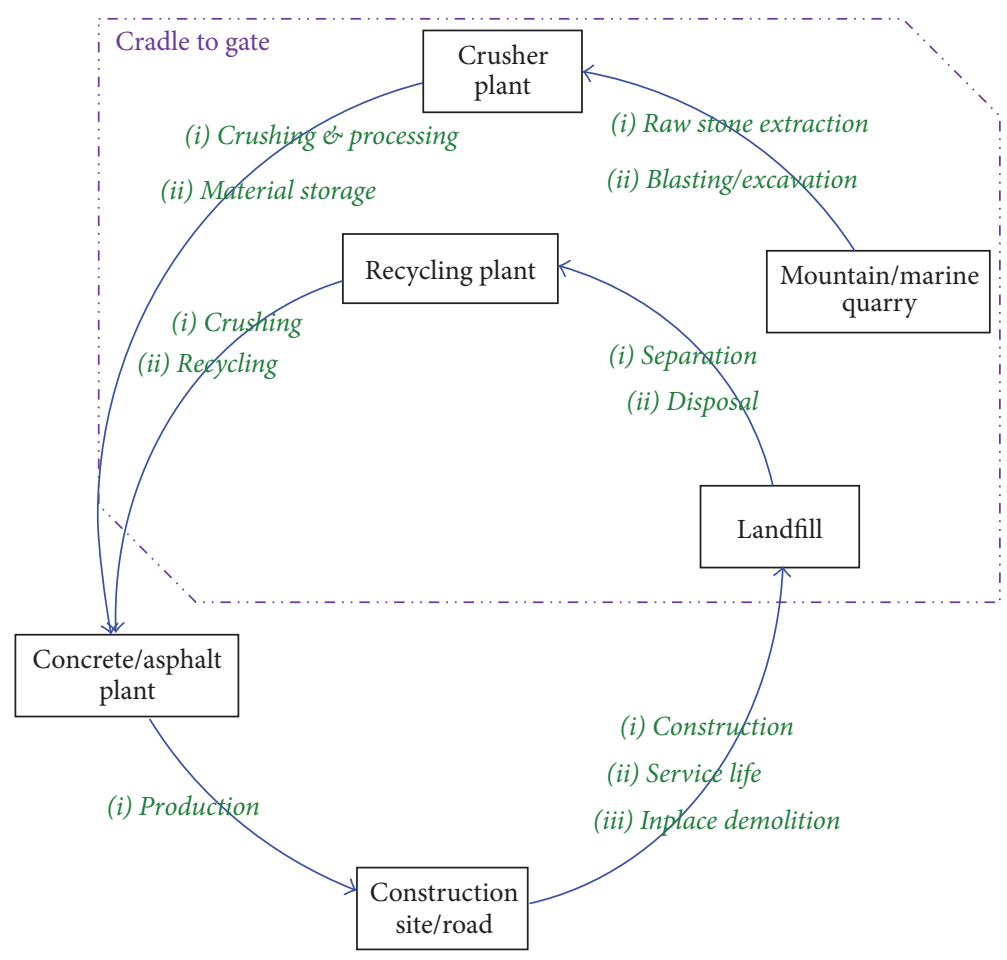

FiguRE 1: Cradle-to-grave and cradle-to-gate life-cycle assessment for aggregate.

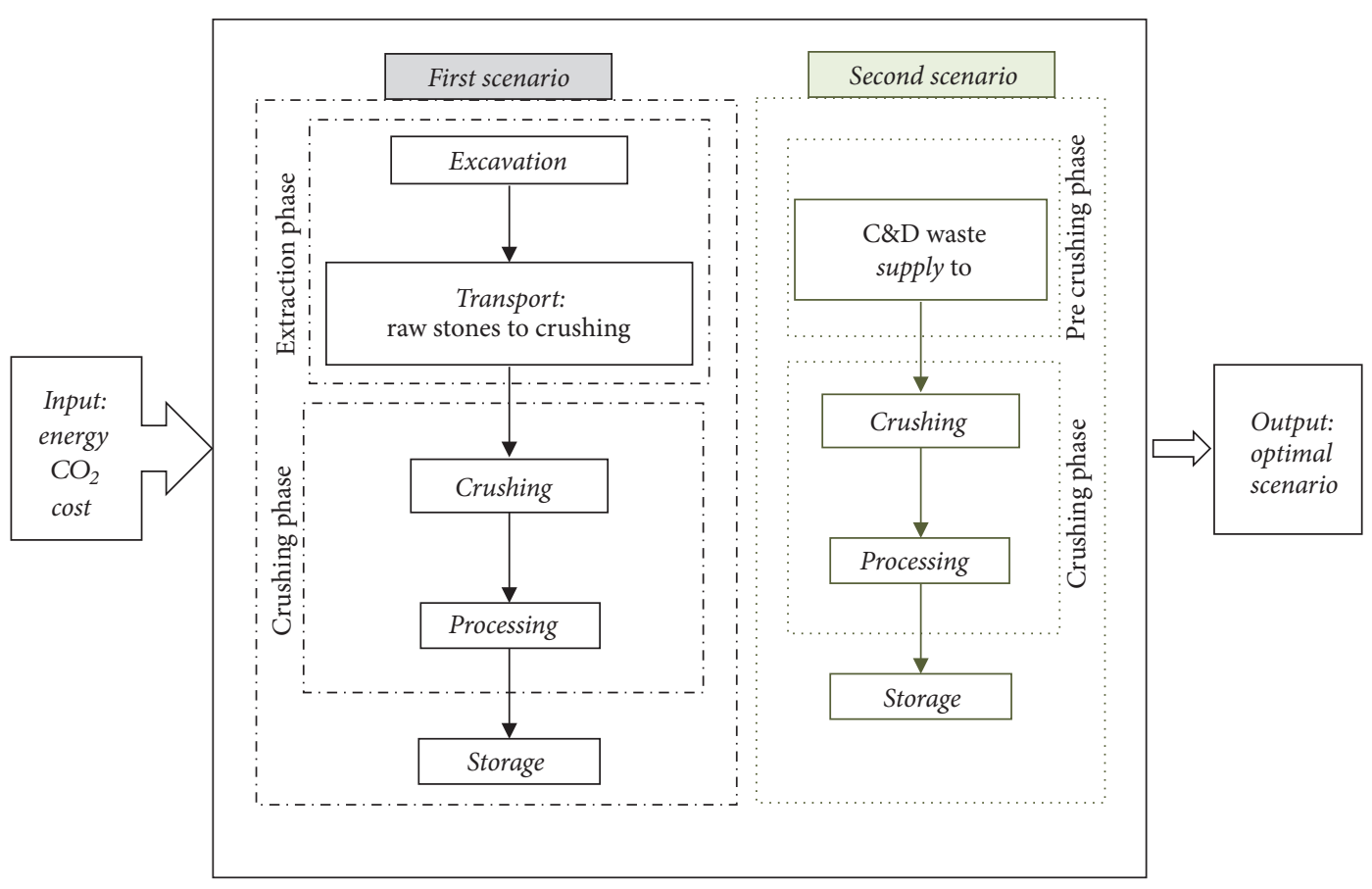

FIGURE 2: Life-cycle sketch of aggregates production.

2.2. Description of the Production and Recycling Facility (Process) and Scenarios. This study is based on two primary scenarios: (i) obtaining natural aggregates from quarry and (ii) obtaining recycled aggregates from C\&D wastes. Aggregates production and recycling processes that consist of crushing operation are normally carried out in two types of fixed (central) and mobile plants [9]. In the present study, the fixed plant type, which is more comprehensive, is investigated.

Production of natural aggregates (scenario 1) consists of two phases: (1) mining the raw material by blasting, excavation, or a combination of both and then transferring the mined rock to the crushing plant and (2) crushing and 
TABLE 1: Scenarios, phases, and used conversion factors of the study.

\begin{tabular}{|c|c|c|c|c|}
\hline$\#$ & Phases & Energy source & Final to primary energy factor & $\mathrm{CO}_{2}$ emission factor \\
\hline \multirow{2}{*}{ Scenario 1} & Step $1=$ extraction \& mining & Diesel & 0.086 & 3.032 \\
\hline & Step $2=$ crushing $\&$ screening & Electricity & 0.29 & 1.2 \\
\hline \multirow{2}{*}{ Scenario 2} & Step $1=$ precrushing & Diesel & 0.086 & 3.032 \\
\hline & Step $2=$ crushing \& screening & Electricity & 0.29 & 1.2 \\
\hline
\end{tabular}

screening the aggregate to the desired size. The second stage is called processing or crushing phase, but this operation as a whole (scenario 1) is also referred to with the terms such as aggregate crushing and aggregate production. The process of recycling aggregates (scenario 2) is similar to natural aggregates production (scenario 1), except that the procedure of crushing and recycling and the used machinery are different [34].

\section{Created Economic and Environmental Analysis-Optimization Model}

To ensure proper environmental (energy consumption and $\mathrm{CO}_{2}$ emission) and economic evaluation, all procedures and processes defined in the inventory of LCA model should be investigated. The basic approach of the majority of countries to aggregates production is based on two mentioned scenarios, in both of which the first phase is based on diesel equipment, and the second phase is based on electric equipment (see Table 1). The energy (diesel and electricity) that is consumed by the plants is called the final energy and is equivalent to energy demand $[34,35]$. But this energy (final) is a product of an initial source known as the primary energy (e.g., crude oil). Both types of energy can serve as appropriate measurement criteria for energy consumption, but this study uses the primary energy for this purpose. In this study, conversion of final energy to primary energy and calculation of $\mathrm{CO}_{2}$ emission due to primary energy consumption are based on the factors given in Table 1.

The model of this study consists of two parts. Since the first objective is the economic and environmental evaluation of aggregate production and recycling plants, the first part of the model covers the variables of cost, energy consumption, and $\mathrm{CO}_{2}$ emission. The second objective, which is to provide an optimal solution, requires the optimization function to be defined in terms of the said variables, so the second part of the model is developed after obtaining the results of the first part. Terms and definitions related to the model and variables of this study are shown in Table 2 . The kilogram oil equivalent (kgoe) unit is employed for energy computation. Similarly, $\mathrm{CO}_{2}$ eq/kgoe is used for $\mathrm{CO}_{2}$ emissions.

3.1. Assessment (the First Part). This section presents the mathematical formulation used for the estimation of cost, energy consumption, and $\mathrm{CO}_{2}$ emission in the two defined scenarios. The final energy consumption (or energy demand) of each step is calculated by (1) that depends on the plant production capacity, power of machinery, and the number of similar apparatuses. According to (2), the total primary energy consumption in each scenario equals the sum of
TABLE 2: Symbols used in this study for modeling.

\begin{tabular}{|c|c|}
\hline Symbol & Description \\
\hline$X_{1}$ & Quantity of natural aggregate (ton) \\
\hline$X_{2}$ & Quantity of recycled aggregate (ton) \\
\hline$r(\%)$ & Natural/recycled aggregate ratio percent \\
\hline$A_{i}$ & Apparatus $i$ \\
\hline$R$ & Production capacity of plant (ton/h) \\
\hline$d$ & Number of activated days in a year (day) \\
\hline$h$ & Number of activated hours in a day (hour) \\
\hline$N_{i}$ & Number of items required for apparatus $i$ \\
\hline$n$ & Number of apparatus in step 1 \\
\hline$m$ & Number of apparatus in step 2 \\
\hline$L$ & Useful life of plant (year) \\
\hline$P_{\mathrm{O}}$ & Price of crude oil (used/kg) \\
\hline FED & $\begin{array}{l}\text { Final energy consumption = final energy demand } \\
(\mathrm{KW} \text { h/ton })\end{array}$ \\
\hline PED & Primary specific energy demand (kgoe/ton) \\
\hline $\mathrm{COE}$ & Specific $\mathrm{CO}_{2}$ eq emission $\left(\mathrm{kg} \mathrm{CO}_{2} \mathrm{eq} /\right.$ ton $)$ \\
\hline$F_{\mathrm{PEF}}$ & Final to primary energy factor \\
\hline$F_{\mathrm{COE}}$ & $\mathrm{CO}_{2}$ emission factor \\
\hline$P_{i}$ & Power of apparatus $i$ \\
\hline$C_{T}$ & Total cost (USD/ton) \\
\hline$C_{E}$ & Energy cost \\
\hline$C_{I}$ & Investment (ownership) cost (USD/ton) \\
\hline$C_{h}$ & $\begin{array}{l}\text { Equipment holding (maintenance) cost of step } i \\
\text { (USD/ton) }\end{array}$ \\
\hline$C_{\mathrm{HR}}$ & Human resource cost of step $i$ (USD/ton) \\
\hline $\mathrm{UP}_{i}$ & Unit price of apparatus $i$ (USD) \\
\hline
\end{tabular}

primary energy consumption of diesel and electric machinery, which is obtained by multiplying their final energy consumption by an energy factor. The total $\mathrm{CO}_{2}$ emission in each scenario (3) is obtained by summing the $\mathrm{CO}_{2}$ emissions of diesel and electric machinery (steps 1 and 2). For any given machinery, this emission is the product of its primary energy consumption and an emission factor. Equations (1) and (2) are related to energy mathematical model, while (3) is $\mathrm{CO}_{2}$ emissions mathematical model.

$$
\begin{aligned}
& \mathrm{FED}_{\text {step 1 }}=\sum_{i=1}^{n} \frac{P_{i} \times N_{i}}{R}, \\
& \mathrm{FED}_{\text {step 2 }}=\sum_{i=n+1}^{m} \frac{P_{i} \times N_{i}}{R},
\end{aligned}
$$




$$
\begin{aligned}
\mathrm{PED}_{T}= & \mathrm{PED}_{\text {step } 1}+\mathrm{PED}_{\text {step } 2} \\
= & \left(\mathrm{FED} \times F_{\mathrm{PEF}}\right)_{\mathrm{STEP} 1}+\left(\mathrm{FED} \times F_{\mathrm{PEF}}\right)_{\mathrm{STEP} 2}, \\
\mathrm{COE}_{T}= & \mathrm{COE}_{\text {step } 1}+\mathrm{COE}_{\text {step } 2} \\
= & \left(\mathrm{PED} \times F_{\mathrm{COE}}\right)_{\mathrm{STEP} 1} \\
& +\left(\mathrm{PED} \times F_{\mathrm{COE}}\right)_{\mathrm{STEP} 2} .
\end{aligned}
$$

As expressed by (4), the annual investment cost for the plant equals the purchase cost of machinery divided by their assumed useful life. The cost of energy consumption of machinery (5) is obtained by multiplication of their primary energy consumption by the price of crude oil (per $\mathrm{kg}$ ). As shown in (6), the total cost of each scenario will be the sum of ownership cost of machinery, cost of their energy consumption, wages of operators, and cost of repair and maintenance. Equations (4) to (6) are related to energy mathematical model.

$$
\begin{aligned}
& \left(C_{I}\right)_{\text {step } 1}=\sum_{i=1}^{n} \frac{\mathrm{UP}_{i} \times N}{L}, \\
& \left(C_{I}\right)_{\text {step 2 }}=\sum_{i=n+1}^{m} \frac{\mathrm{UP}_{i} \times N}{L} \\
& \left(C_{E}\right)_{\mathrm{STEP} 1}=\mathrm{PED}_{\text {step } 1} \times P_{O}, \\
& \left(C_{E}\right)_{\text {STEP 2 }}=\text { PED }_{\text {step } 2} \times P_{O} \text {, } \\
& C_{T}=C_{\text {step 1 }}+C_{\text {step } 2} \\
& =\left(C_{E}+\frac{C_{I}+C_{h}+C_{\mathrm{HR}}}{d \times h \times R}\right)_{\mathrm{STEP} 1} \\
& +\left(C_{E}+\frac{C_{I}+C_{h}+C_{\mathrm{HR}}}{d \times h \times R}\right)_{\mathrm{STEP} 2} .
\end{aligned}
$$

3.2. Optimization (the Second Part). The second part of modeling is based on the results of the first part. By combining the described variables for both scenarios, the optimal amount of natural and recycled aggregates, thus the optimal mixing ratio can be estimated. The objective function obtained from the interaction of research variable is expressed by (7). This equation is combination mathematical model of energy consumption, $\mathrm{CO}_{2}$ emissions, and cost for optimization.

$$
\begin{aligned}
\min & Z(x) \\
= & \left(\mathrm{COE}_{T} \times \mathrm{PED}_{T} \times C_{T}\right)_{\text {Scenario } 1} X_{1}^{3} \\
& +\left(\mathrm{COE}_{T} \times \mathrm{PED}_{T} \times C_{T}\right)_{\text {Scenario } 2} X_{2}^{3} .
\end{aligned}
$$

Since the objective of optimization is to estimate the optimal weight of each type of aggregate, the sum of both types of aggregates, both being positive values, is equal to one ton. These two constraints are defined by (8). Next, maximum or minimum amount of NA and RA can be limited with qualitative constraints based on experimental studies and depending on the type of application such as [16] research.
After obtaining the optimum values of aggregates, one can define a third scenario, that is, an optimal scenario combining the other two approaches (see Figure 2), subject to

$$
\begin{gathered}
X_{1}+X_{2}=1, \\
X_{1}, X_{2} \geq 0 .
\end{gathered}
$$

3.3. Case Study. Based on the concept of the analysis in this paper, a program is created via Java which is a programming language; screen of the computer generated program is shown in Figure 3. To evaluate and validate the defined model, two aggregate production and recycling plants, each having a capacity of $200 \mathrm{t} / \mathrm{h}$, are studied. The first plant, chosen for scenario 1, is an aggregate production plant in the west of Tehran (Akam Gravel company), and the second plant, chosen for scenario 2, is assumed based on a business proposal by a Chinese firm (a 200 tons/hour proposed plant by Zhengzhou Yifan Machinery Co., Ltd.). Tables 3 and 4 show the specifications of machinery in these two plants. Typically, working hours of such centers are limited to 8 hours a day to control their environmental effect such as noise and air pollution. All calculations are carried for the period of one year consisting of 12 months, each with 30 working days.

\section{Results and Discussions}

The model was coded based on the defined formulas and relationships, and specifications of the case study were imported into the developed program. Since the secondary objective of the study was the described optimization, the third scenario, which was created based on the optimal values, was adopted as the optimal scenario and solution. The results obtained for the variables of this study are shown in Table 5.

Given the results obtained for the combination of production of NA and RA, the optimal ratio was found to be $50 \%$. As a result, the values of energy, $\mathrm{CO}_{2}$ emission, and cost for scenario 3 (optimal scenario) are the averages of corresponding values in scenarios 1 and 2. Table 6 shows the detailed results for all three scenarios which fall within the ranges which have been used in one of the environmental studies related to life-cycle concrete block [36].

According to the results presented in Table 6, in scenario 1 , the major consumer of energy is the crushing phase (step 2), which has caused a significant increase in total energy consumption, yet the $\mathrm{CO}_{2}$ emission produced due to extraction phase (step 1) is greater than the amount produced due to crushing phase. This is because extraction phase relies on diesel machinery, which has a higher $\mathrm{CO}_{2}$ emission factor than electric machinery used in the next phase. It means the energy consumption function is most sensitive to electric equipment, whereas the $\mathrm{CO}_{2}$ emissions function is most sensitive to diesel consumer equipment. In scenario 2 , the absence of large diesel machinery in step 1 has led to low energy consumption, thus making step 2 the major energy consumer. Since scenario 3 is a combined scenario, its major energy consumer and $\mathrm{CO}_{2}$ emission source are, respectively, the crushing phase and the extraction phase. 
TABLE 3: The specifications of machinery in the production plant.

\begin{tabular}{|c|c|c|c|c|c|c|c|}
\hline \multicolumn{8}{|c|}{ Scenario 1} \\
\hline Step & Symbol & Machine \& model & $P(\mathrm{KW})$ & $N$ & UP (USD) & $C_{\mathrm{HR}}(\mathrm{USD} /$ year) & $C_{h}(\mathrm{USD} /$ year $)$ \\
\hline \multirow{5}{*}{1} & $\mathrm{~A} 1$ & Bulldozer. Komatsu D155A-2, efficiency = 71\% & 238.6 & 2 & 140541 & 24000 & 23892 \\
\hline & $\mathrm{A} 2$ & Hydraulic excavator. Komatsu PC 600-7, efficiency $=75 \%$ & 287 & 3 & 129730 & 36000 & 35805 \\
\hline & A3 & Wheel loader. Komatsu WA420-3, efficiency = 75\% & 162 & 2 & 67027 & 24000 & 12065 \\
\hline & A4 & Lorry truck. Benz Wh 2624, efficiency = 82\% & 179 & 6 & 56757 & 72000 & 28265 \\
\hline & A5 & Backhoe loader. HEPCO B90B, efficiency = 65\% & 72 & 1 & 29189 & 12000 & 2277 \\
\hline \multirow{15}{*}{2} & A6 & Primary-jaw crusher & 165 & 1 & 31216 & \multirow{15}{*}{37920} & 4865 \\
\hline & A7 & Secondary-hydrocone crusher & 125 & 2 & 26486 & & 13946 \\
\hline & A8 & Tertiary-impact crusher & 195 & 1 & 26351 & & 7622 \\
\hline & A9 & Vibrating feeder & 16 & 2 & 10811 & & 2789 \\
\hline & $\mathrm{A} 10$ & Vibrating screening & 19 & 3 & 15405 & & 4962 \\
\hline & A11 & Bucket-typed sand washing machine & 18 & 1 & 12162 & & 1459 \\
\hline & $\mathrm{A} 12$ & Pan-typed aggregate washing machine & 20 & 3 & 7568 & & 2919 \\
\hline & A13 & Control panel & - & 1 & 19595 & & 85 \\
\hline & A14 & Steel structure, 7.85 tons & - & 1 & 8486 & & 950 \\
\hline & $\mathrm{A} 15$ & Conveyor belt $1.2 \times 35$ & 18 & 4 & 12297 & & 7568 \\
\hline & A16 & Conveyor belt $1.2 \times 21$ & 12.5 & 4 & 7095 & & 4541 \\
\hline & A17 & Conveyor belt $1 \times 15$ & 8 & 3 & 4622 & & 2311 \\
\hline & A18 & Conveyor belt $1 \times 8$ & 6.5 & 2 & 2270 & & 800 \\
\hline & A19 & Conveyor belt $1.2 \times 4$ & 5 & 1 & 1081 & & 200 \\
\hline & A20 & Conveyor belt $1 \times 3.5$ & 4 & 2 & 1041 & & 341 \\
\hline
\end{tabular}

TABLE 4: The specifications of machinery in the recycling plant.

\begin{tabular}{|c|c|c|c|c|c|c|c|}
\hline \multicolumn{8}{|c|}{ Scenario 2} \\
\hline Step & Symbol & Machine \& model & $P(\mathrm{KW})$ & $N$ & UP (USD) & $C_{\mathrm{HR}}(\mathrm{USD} /$ year) & $C_{h}$ (USD/year) \\
\hline \multirow{2}{*}{1} & A 21 & Hydraulic excavator. Komatsu PC 200-7, efficiency = 70\% & 107 & 1 & 47568 & 12000 & 3948 \\
\hline & $\mathrm{A} 22$ & Wheel loader. VOLVO L120F, efficiency $=73 \%$ & 179 & 1 & 105405 & 12000 & 9276 \\
\hline \multirow{19}{*}{2} & A23 & Vibrating feeder & 15 & 1 & 15860 & \multirow{19}{*}{56880} & 1849 \\
\hline & A 24 & Primary-jaw crusher & 90 & 1 & 66270 & & 8757 \\
\hline & A 25 & Secondary-impact crusher & 250 & 1 & 57820 & & 10541 \\
\hline & A26 & Vibrating screening & 30 & 1 & 31730 & & 2432 \\
\hline & A 27 & Magnetic separator & 3 & 1 & 11200 & & 1622 \\
\hline & A28 & Soft products separator & 5.5 & 2 & 11670 & & 3892 \\
\hline & A29 & Dust collector & 85 & 1 & 67000 & & 6486 \\
\hline & $\mathrm{A} 30$ & Control panel & - & 1 & 15240 & & 85 \\
\hline & A31 & Steel structure, 4 tons & - & 1 & 7300 & & 715 \\
\hline & A32 & Conveyor belt $1 \times 11$ & 7.5 & 1 & 6850 & & 595 \\
\hline & A33 & Conveyor belt $1.2 \times 10$ & 5.5 & 1 & 8970 & & 541 \\
\hline & A 34 & Conveyor belt $1 \times 19$ & 11 & 1 & 9250 & & 1027 \\
\hline & A35 & Conveyor belt $1 \times 25$ & 15 & 1 & 11050 & & 1351 \\
\hline & A36 & Conveyor belt $1 \times 10$ & 4 & 1 & 6545 & & 541 \\
\hline & A37 & Conveyor belt $0.8 \times 16$ & 7.5 & 1 & 6500 & & 865 \\
\hline & A38 & Conveyor belt $0.65 \times 20$ & 7.5 & 2 & 6120 & & 2162 \\
\hline & A39 & Conveyor belt $0.65 \times 12$ & 5.5 & 1 & 4600 & & 649 \\
\hline & $\mathrm{A} 40$ & Conveyor belt $0.65 \times 15$ & 5.5 & 1 & 5170 & & 811 \\
\hline & A41 & Conveyor belt $0.65 \times 18$ & 5.5 & 1 & 5470 & & 973 \\
\hline
\end{tabular}

$R=200 \mathrm{t} / \mathrm{h}, d=300, h=8, n=2, m=19, L=20$ years, and $P_{\mathrm{O}}=0.34 \mathrm{USD} / \mathrm{kg}$. 


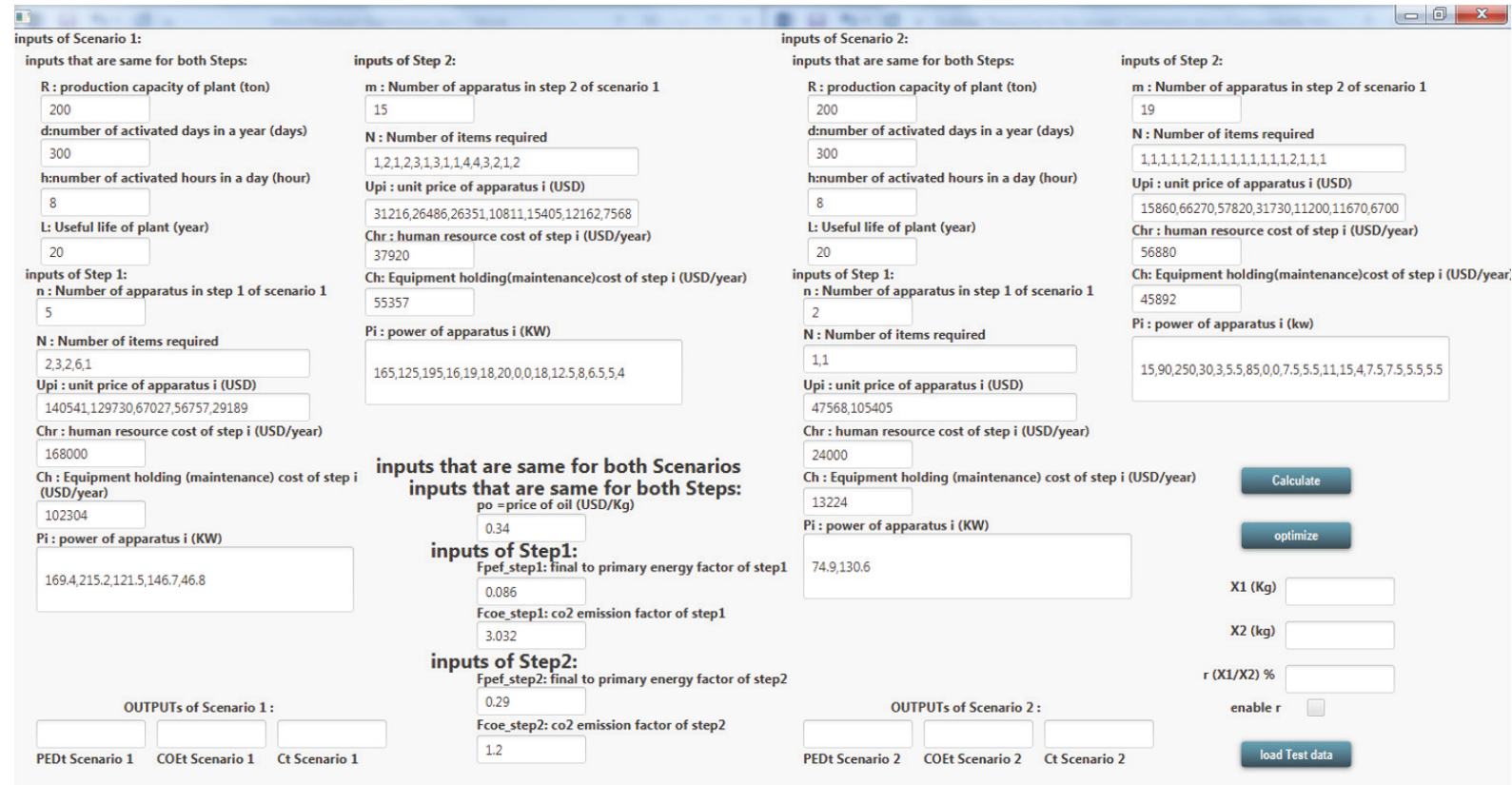

FIGURE 3: Software program created for analysis of the model via Java programming language.

TABLE 5: The results for the variables of this study.

\begin{tabular}{|c|c|c|c|c|c|}
\hline Variable & $\mathrm{PED}_{T}$ (kgoe/ton) & $\mathrm{COE}_{T}\left(\mathrm{~kg} \mathrm{CO} \mathrm{CO}_{2} \mathrm{eq}\right.$ ton $)$ & $C_{T}$ (USD/ton) & $X_{1}$ (ton) & $X_{2}$ (ton) \\
\hline Scenario 1 & 2.3027 & 4.4609 & 1.6981 & \multirow{2}{*}{0.5} & \multirow{2}{*}{0.5} \\
\hline Scenario 2 & 0.9091 & 1.2529 & 0.6555 & & \\
\hline
\end{tabular}

TABLE 6: The economic and environmental detailed results for the research scenarios.

\begin{tabular}{|c|c|c|c|c|}
\hline Aggregate obtaining type & Processing step & $\begin{array}{c}\text { Primary specific energy } \\
\text { demand (kgoe/ton) }\end{array}$ & $\begin{array}{c}\text { Specific } \mathrm{CO}_{2} \text { eq emission } \\
\left(\mathrm{kg} \mathrm{CO} \mathrm{CO}_{2} \text { eq/ton }\right)\end{array}$ & Cost (USD/ton) \\
\hline \multirow{3}{*}{ Scenario 1} & Extraction \& mining & 0.9267 & 2.8097 & 1.0008 \\
\hline & Crushing \& screening & 1.3761 & 1.6513 & 0.6976 \\
\hline & Total & 2.3027 & 4.4609 & 1.6981 \\
\hline \multirow{3}{*}{ Scenario 2} & Extraction \& mining & 0.0884 & 0.2680 & 0.1235 \\
\hline & Crushing \& screening & 0.8207 & 0.9848 & 0.5319 \\
\hline & Total & 0.9091 & 1.2529 & 0.6555 \\
\hline \multirow{3}{*}{ Scenario 3} & Extraction \& mining & 0.5075 & 1.5388 & 0.5620 \\
\hline & Crushing \& screening & 1.0984 & 1.3181 & 0.6148 \\
\hline & Total & 1.6059 & 2.8569 & 1.1768 \\
\hline \multicolumn{2}{|c|}{ Saving percent (third scenario/first scenario) } & $30 \%$ & $36 \%$ & $31 \%$ \\
\hline
\end{tabular}

The chart of final status of the three research scenarios is illustrated in Figure 4. The values of research variables are also plotted in a bar chart. Figure 4 indicates that scenario 3 (optimized scenario) has resulted in more balanced values than the others. Thus, scenario 3 would be an optimal solution for reducing environmental consequences of aggregate mines and therefore an eco-friendly alternative in this respect. As shown in Table 6, scenario 3 is $30 \%$ more economic and has $36 \%$ lower $\mathrm{CO}_{2}$ emission and $31 \%$ lower energy consumption than scenario 1 ; the improvements demonstrate the effectiveness of the third scenario but it requires a sensitivity analysis.

The $\mathrm{CO}_{2}$ emission is function of $\mathrm{CO}_{2}$ emission factor and energy consumption which has two operational phases or two steps. Thus, we need to discuss applying the $\mathrm{CO}_{2}$ emissions sensitivity to the related parameters. According to $[34,37]$, uncertainties in LCA of waste management systems for recycling process consist of scenario uncertainty and parameter uncertainty. As the aim of perturbation analysis is to determine the effect of an arbitrary change of single 


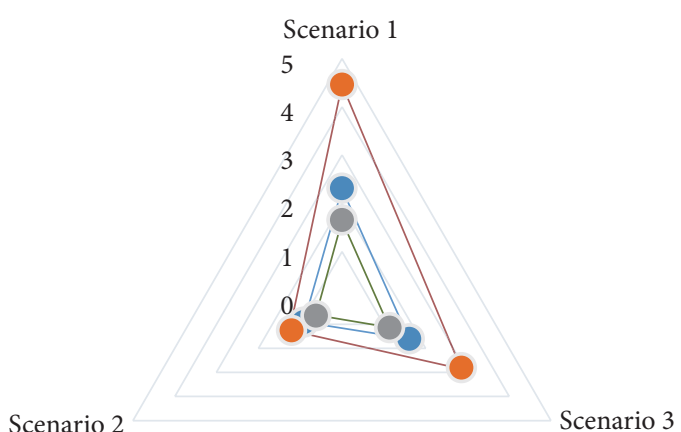

Primary energy demand (kgoe/ton)

$\mathrm{CO}_{2}$ eq emission ( $\mathrm{kg} \mathrm{CO}_{2}$ eq/ton)

Cost (USD/ton)

(a)

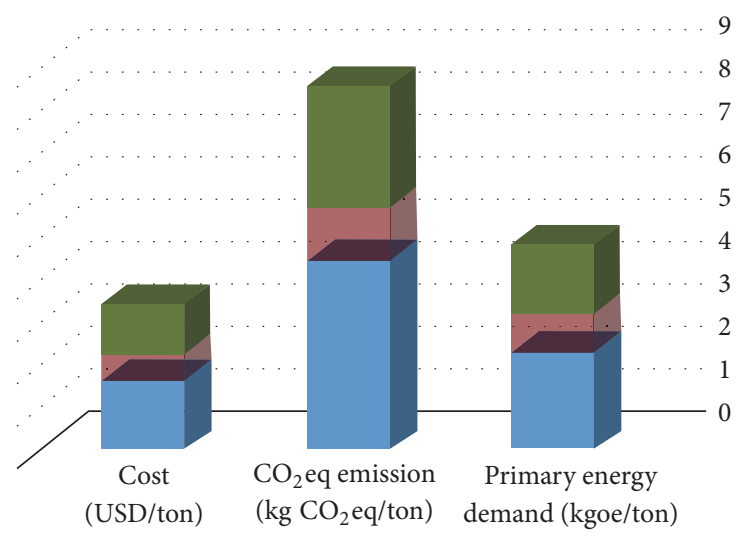

Scenario 1

Scenario 2

Scenario 3

FIgURE 4: (a) The final status of the three research scenarios. (b) The bar chart of research variables.

TABLE 7: Sensitivity coefficient of the $\mathrm{CO}_{2}$ emission model to each parameter.

\begin{tabular}{lccc}
\hline Parameter & $\begin{array}{c}\text { Scenario 1 } \\
(100 \% \text { NA \& 0\% RA) }\end{array}$ & $\begin{array}{c}\text { Scenario 3 } \\
\text { (50\% NA \& 50\% RA) }\end{array}$ & $\begin{array}{c}\text { Scenario 2 } \\
(0 \% \text { NA \& 100\% RA) }\end{array}$ \\
\hline Diesel consumption (precrushing phase) & 3.0 & 3.0 & 3.0 \\
Electricity consumption (crushing phase) & 1.2 & 1.2 & 1.2 \\
Emission conversion factor of electricity & 660.5 & 527.2 & 393.9 \\
Emission conversion factor of diesel & 444.3 & 243.4 & 42.4 \\
\hline
\end{tabular}

parameter values on the model's result, the sensitivity coefficient (SC) is the ratio between the two generated absolutes [37]. In the present study, each parameter value is individually varied by a small increase; then the variation of the result is calculated. According to $[34,37]$, the sensitivity coefficient could be calculated by (9). Based on (3), the $\mathrm{CO}_{2}$ emission is function of $\mathrm{CO}_{2}$ emission factor and energy consumption which has two operational phases or two steps. Thus, we need to discuss applying the $\mathrm{CO}_{2}$ emissions sensitivity. In other words, as $\mathrm{CO}_{2}$ emission depends on energy consumption, it does not need discussion. The results of sensitivity coefficient of $\mathrm{CO}_{2}$ emission model to each parameter are summarized in Table 7. According to Table 7, the SC of emission conversion factors is higher than that of energy consumption. Thus, the $\mathrm{CO}_{2}$ emission model is the most sensitive to parameters of emission conversion factors. Furthermore, evaluation of all scenarios demonstrates that the sensitivity coefficient of the emission rises by increasing the percentage of NA (or decreasing the RA). Thus, the $\mathrm{CO}_{2}$ emission model is most sensitive to the first scenario.

$$
\mathrm{SC}=\frac{\Delta \text { result }}{\Delta \text { parameter }} .
$$

\section{Conclusions}

Aggregates, both natural (NA) and recycled (RA), have various structural and nonstructural applications. For the production of natural aggregates (represented in this study by scenario 1), raw materials should be mined from quarries and crushed and screened in the crushing plants. Production of recycled aggregates (represented in this study by scenario 2) is based on recycling of construction and demolition (C\&D) wastes at dedicated recycling plants. The fuels consumed by the machinery of these two types of plants are diesel and electricity. This study had two objectives. The first objective was the environmental (energy consumption and $\mathrm{CO}_{2}$ emissions) and economic (production cost) evaluation of scenario 1 (NA) and scenario 2 (RA). The main variables of this part of the study were the production cost, energy consumption, and $\mathrm{CO}_{2}$ emissions. To estimate these variables, mathematical relations of the life-cycle of aggregates in both scenarios were introduced and formulated. The second objective of the study was to estimate the optimal ratio of production of NA and RA based on the results of life-cycle analysis (LCA). By achieving the optimal mixing ratio, the previous two scenarios combined together and generated third scenario in an optimal approach. Objective function of the optimization problem was formulated using the outputs of the LCA. This function can be developed with specific quantitative constraints, depending on the type of application, site material, and experimental test, in order to introduce further complexity to the function or improve the accuracy of its estimations.

The defined formulas and relationships were used to code a computer program via Java programming language. 
Software for assessment and optimizing the combination ratio of NA and RA was produced. The developed model was tested in a case study to evaluate its performance. In this study, information of two aggregates production and recycling plants was analyzed. The results of the first part (lifecycle assessment) showed that diesel machinery have a lower energy consumption and yet higher $\mathrm{CO}_{2}$ emission than electric machinery. It was found that energy consumption, $\mathrm{CO}_{2}$ emission, and the costs of scenario 2 are less than those of scenario 1. After optimization, the optimal ratio of aggregates combination was found to be $50 \%$. Energy consumption, $\mathrm{CO}_{2}$ emissions, and the cost of scenario 3 were found to be balanced values ranging between the values obtained from the previous scenarios. According to the results of life-cycle analysis, energy consumption, $\mathrm{CO}_{2}$ emissions, and production cost of one ton of combined aggregates (scenario 3) are 1.6 kilogram oil equivalent (kgoe), $2.85 \mathrm{CO}_{2}$ eq., and $1.17 \mathrm{USD}$, which are $30 \%, 36 \%$, and $31 \%$ better than their respective values in scenario 1 . Generalization of values obtained in the first scenario to the total amount of aggregates produced and consumed in major countries like US highlights the true extent of environmental impacts associated with this issue. Thus, the least that can be done toward mitigating the undesirable environmental and economic effects of overexploitation of stone quarries is to adopt a combined solution like the third scenario discussed in this paper.

\section{Conflicts of Interest}

The authors declare no conflicts of interest.

\section{Acknowledgments}

The authors gratefully acknowledge both companies for giving the required data for the study.

\section{References}

[1] A. Arulrajah, J. Piratheepan, M. M. Disfani, and M. W. Bo, "Geotechnical and geoenvironmental properties of recycled construction and demolition materials in pavement subbase applications," Journal of Materials in Civil Engineering, vol. 25, no. 8, pp. 1077-1088, 2013.

[2] V. W. Y. Tam, L. Tam, and K. N. Le, "Cross-cultural comparison of concrete recycling decision-making and implementation in construction industry," Waste Management, vol. 30, no. 2, pp. 291-297, 2010.

[3] Y.-C. Liang, Z.-M. Ye, F. Vernerey, and Y. Xi, "Development of processing methods to improve strength of concrete with $100 \%$ recycled coarse aggregate," Journal of Materials in Civil Engineering, vol. 27, no. 5, Article ID 04014163, 2015.

[4] T. Huang, F. Shi, H. Tanikawa, J. Fei, and J. Han, "Materials demand and environmental impact of buildings construction and demolition in China based on dynamic material flow analysis," Resources, Conservation and Recycling, vol. 72, pp. 91101, 2013.

[5] J. Han and J. K. Thakur, "Use of Geosynthetics to Stabilize Recycled Aggregates in Roadway Construction," in Proceedings of the International Conference on Sustainable Design, Engineering, and Construction 2012, Fort Worth, Tex, USA, 7-9 November 2012.

[6] M. D. Saghafi and Z. S. Hosseini Teshnizi, "Recycling value of building materials in building assessment systems," Energy and Buildings, vol. 43, no. 11, pp. 3181-3188, 2011.

[7] D.-Y. Oh, T. Noguchi, R. Kitagaki, and W.-J. Park, "CO2 emission reduction by reuse of building material waste in the Japanese cement industry," Renewable and Sustainable Energy Reviews, vol. 38, pp. 796-810, 2014.

[8] A. Coelho and J. D. Brito, "Environmental analysis of a construction and demolition waste recycling plant in Portugal - Part I: Energy consumption and CO2 emissions," Waste Management, vol. 33, no. 5, pp. 1258-1267, 2013.

[9] W. Zhao, R. B. Leeftink, and V. S. Rotter, "Evaluation of the economic feasibility for the recycling of construction and demolition waste in China-The case of Chongqing," Resources, Conservation and Recycling, vol. 54, no. 6, pp. 377-389, 2010.

[10] G. Petkovic, C. J. Engelsen, A.-O. Håøya, and G. Breedveld, "Environmental impact from the use of recycled materials in road construction: Method for decision-making in Norway," Resources, Conservation and Recycling, vol. 42, no. 3, pp. 249264, 2004.

[11] M. M. Sabai, M. G. D. M. Cox, R. R. Mato, E. L. C. Egmond, and J. J. N. Lichtenberg, "Concrete block production from construction and demolition waste in Tanzania," Resources, Conservation and Recycling, vol. 72, pp. 9-19, 2013.

[12] F. Yuan, L.-Y. Shen, and Q.-M. Li, "Emergy analysis of the recycling options for construction and demolition waste," Waste Management, vol. 31, no. 12, pp. 2503-2511, 2011.

[13] V. W. Y. Tam and C. M. Tam, "Evaluations of existing waste recycling methods: A Hong Kong study," Building and Environment, vol. 41, no. 12, pp. 1649-1660, 2006.

[14] P. K. Kolay and M. Akentuna, "Characterization and utilization of recycled concrete aggregate from Illinois as a construction material," in Proceedings of the 2014 Congress on GeoCharacterization and Modeling for Sustainability, Geo-Congress 2014, pp. 3561-3570, Atlanta, Ga, USA, February 2014.

[15] S. Lotfi, J. Deja, P. Rem, R. Mróz, E. Van Roekel, and H. Van Der Stelt, "Mechanical recycling of EOL concrete into high-grade aggregates," Resources, Conservation and Recycling, vol. 87, pp. 117-125, 2014.

[16] H. Kang and S.-H. Kee, "Improving the Quality of Mixed Recycled Coarse Aggregates from Construction and Demolition Waste Using Heavy Media Separation with $\mathrm{Fe}_{3} \mathrm{O}_{4}$ Suspension," Advances in Materials Science and Engineering, vol. 2017, Article ID 8753659, 12 pages, 2017.

[17] C. Xue, A. Shen, Y. Guo, and T. He, "Utilization of Construction Waste Composite Powder Materials as Cementitious Materials in Small-Scale Prefabricated Concrete," Advances in Materials Science and Engineering, vol. 2016, Article ID 8947935, 11 pages, 2016.

[18] X. Ma and Z. Wang, "Effect of ground waste concrete powder on cement properties," Advances in Materials Science and Engineering, vol. 2013, Article ID 918294, 5 pages, 2013.

[19] L. Ooshaksaraie and A. Mardookhpour, "A rule-based expert system for construction and demolition waste management," American Journal of Environmental Sciences, vol. 7, no. 6, pp. 492-498, 2011.

[20] G. A. Blengini, "Life cycle of buildings, demolition and recycling potential: A case study in Turin, Italy," Building and Environment, vol. 44, no. 2, pp. 319-330, 2009. 
[21] M. D. Bovea and J. C. Powell, "Developments in life cycle assessment applied to evaluate the environmental performance of construction and demolition wastes," Waste Management, vol. 50, pp. 151-172, 2016.

[22] J. Park, S. Tae, and T. Kim, "Life cycle CO 2 assessment of concrete by compressive strength on construction site in Korea," Renewable and Sustainable Energy Reviews, vol. 16, no. 5, pp. 2940-2946, 2012.

[23] M. De Schepper, P. Van den Heede, I. Van Driessche, and N. De Belie, "Life Cycle Assessment of Completely Recyclable Concrete," Materials, vol. 7, no. 8, pp. 6010-6027, 2014.

[24] E. R. Teixeira, R. Mateus, A. F. Camõesa, L. Bragança, and F. G. Branco, "Comparative environmental life-cycle analysis of concretes using biomass and coal fly ashes as partial cement replacement material," Journal of Cleaner Production, vol. 112, pp. 2221-2230, 2016.

[25] C. K. Chau, T. M. Leung, and W. Y. Ng, "A review on life cycle assessment, life cycle energy assessment and life cycle carbon emissions assessment on buildings," Applied Energy, vol. 143, pp. 395-413, 2015.

[26] M. Ristimäki, A. Säynäjoki, J. Heinonen, and S. Junnila, "Combining life cycle costing and life cycle assessment for an analysis of a new residential district energy system design," Energy, vol. 63, pp. 168-179, 2013.

[27] S. D. Mangan and G. K. Oral, "Assessment of residential building performances for the different climate zones of Turkey in terms of life cycle energy and cost efficiency," Energy and Buildings, vol. 110, pp. 362-376, 2016.

[28] H. Islam, M. Jollands, and S. Setunge, "Life cycle assessment and life cycle cost implication of residential buildings - A review," Renewable and Sustainable Energy Reviews, vol. 42, pp. 129-140, 2015.

[29] H. Islam, M. Jollands, S. Setunge, N. Haque, and M. A. Bhuiyan, "Life cycle assessment and life cycle cost implications for roofing and floor designs in residential buildings," Energy and Buildings, vol. 104, article no. 6010, pp. 250-263, 2015.

[30] H. Islam, M. Jollands, S. Setunge, I. Ahmed, and N. Haque, "Life cycle assessment and life cycle cost implications of wall assemblages designs," Energy and Buildings, vol. 84, pp. 33-45, 2014.

[31] A. A. Butt, S. Toller, and B. Birgisson, "Life cycle assessment for the green procurement of roads: A way forward," Journal of Cleaner Production, vol. 90, pp. 163-170, 2015.

[32] A. Arulrajah, M. M. Disfani, S. Horpibulsuk, C. Suksiripattanapong, and N. Prongmanee, "Physical properties and shear strength responses of recycled construction and demolition materials in unbound pavement base/subbase applications," Construction and Building Materials, vol. 58, pp. 245-257, 2014.

[33] International Standard Organization, "ISO 14040: Environmental Management-Life Cycle Assessment-Principles and Framework," 2006.

[34] M. Ghanbari, A. M. Abbasi, and M. Ravanshadnia, "Production of natural and recycled aggregates: the environmental impacts of energy consumption and $\mathrm{CO}_{2}$ emissions," Journal of Material Cycles and Waste Management, pp. 1-13, 2017.

[35] M. Ghanbari, M. A. Abbasi, and M. Ravanshadnia, "Environmental life cycle assessment and cost analysis of aggregate production industries compared with hybrid scenario," Applied Ecology and Environmental Research, vol. 15, no. 3, pp. 15771593, 2017.

[36] L. S. Oliveira, S. A. Pacca, and V. M. John, "Variability in the life cycle of concrete block $\mathrm{CO} 2$ emissions and cumulative energy demand in the Brazilian Market," Construction and Building Materials, vol. 114, pp. 588-594, 2016.

[37] J. Clavreul, D. Guyonnet, and T. H. Christensen, "Quantifying uncertainty in LCA-modelling of waste management systems," Waste Management, vol. 32, no. 12, pp. 2482-2495, 2012. 

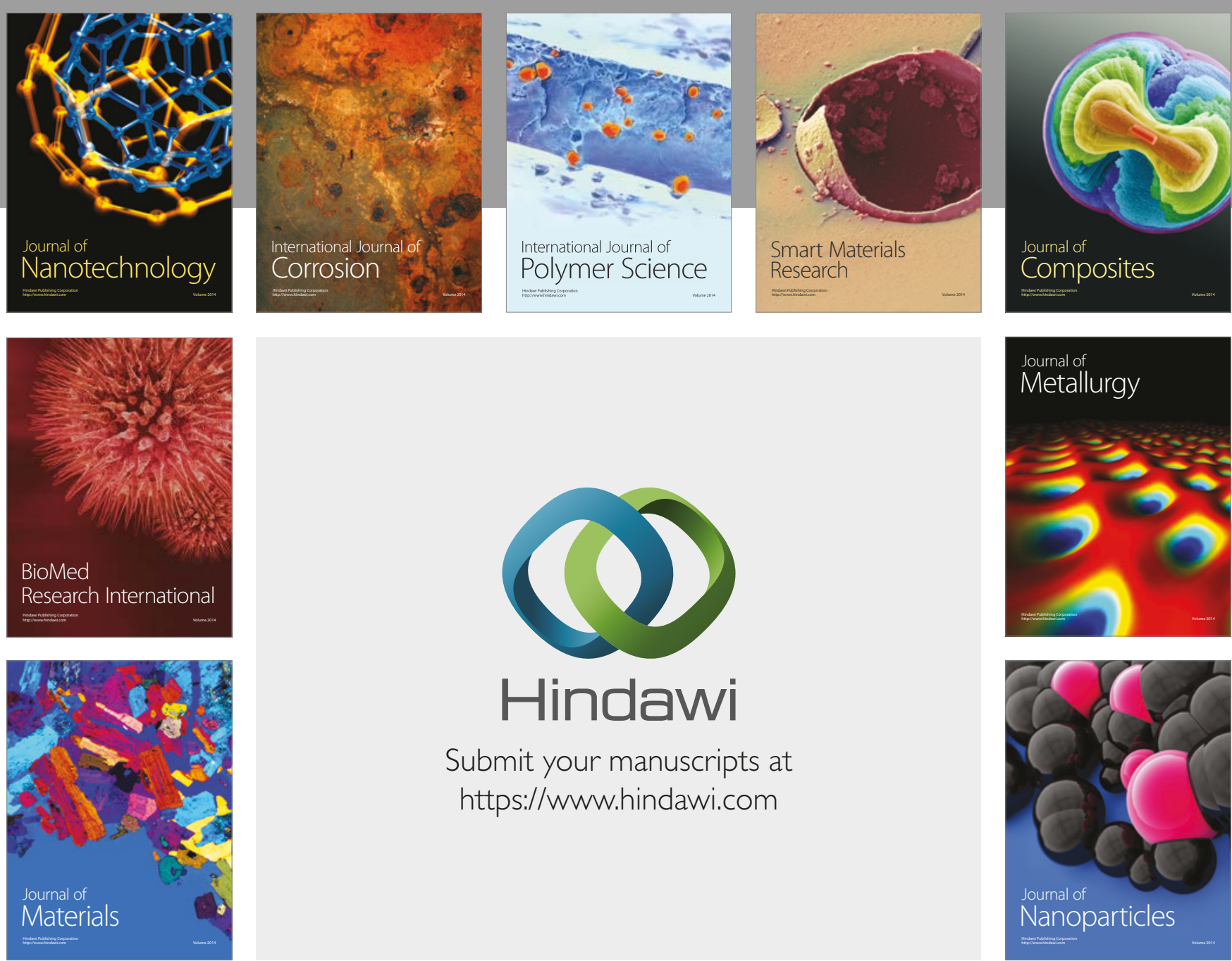

\section{Hindawi}

Submit your manuscripts at

https://www.hindawi.com
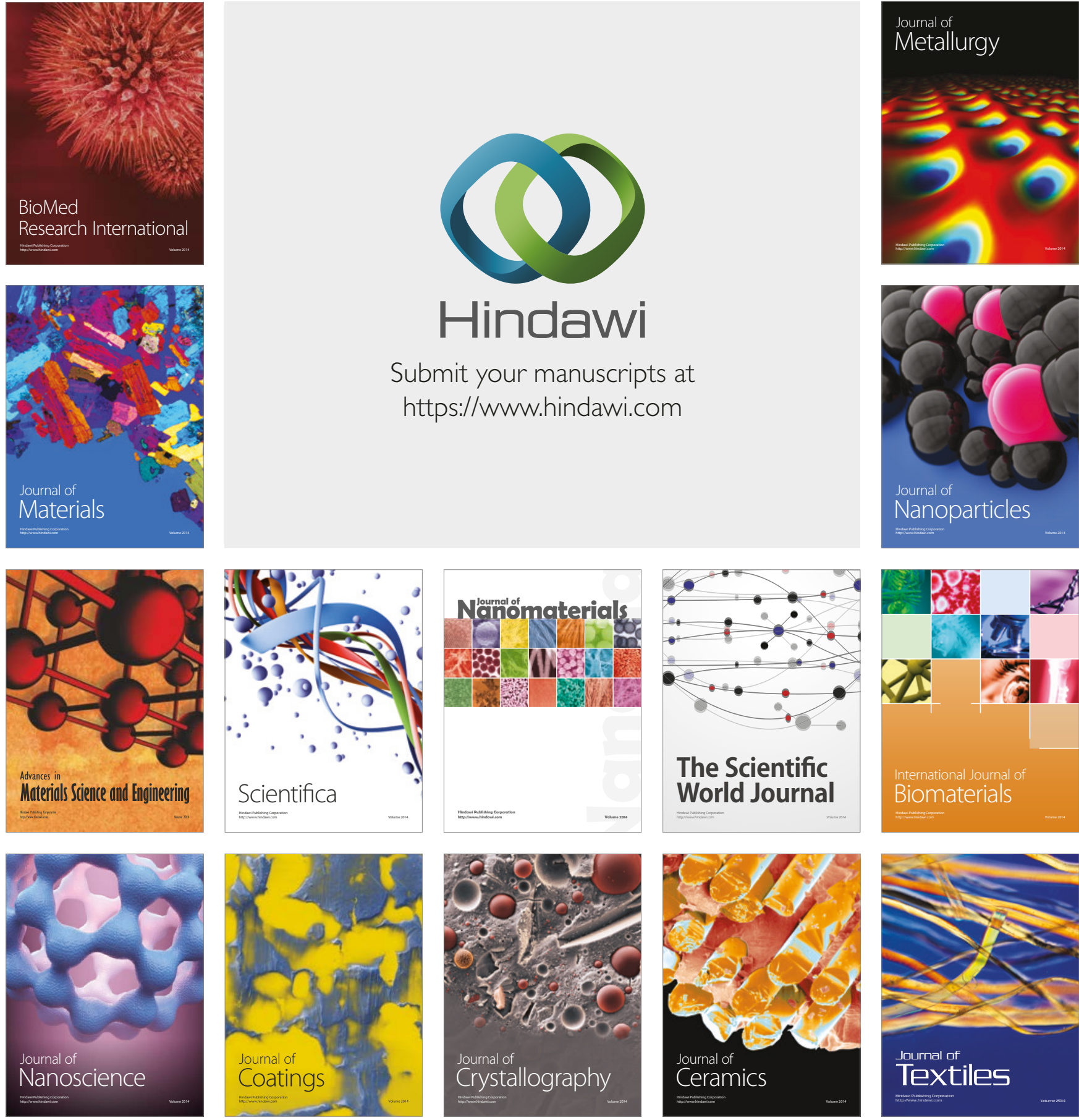

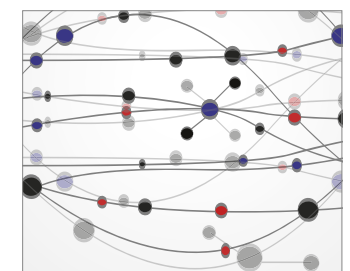

The Scientific World Journal
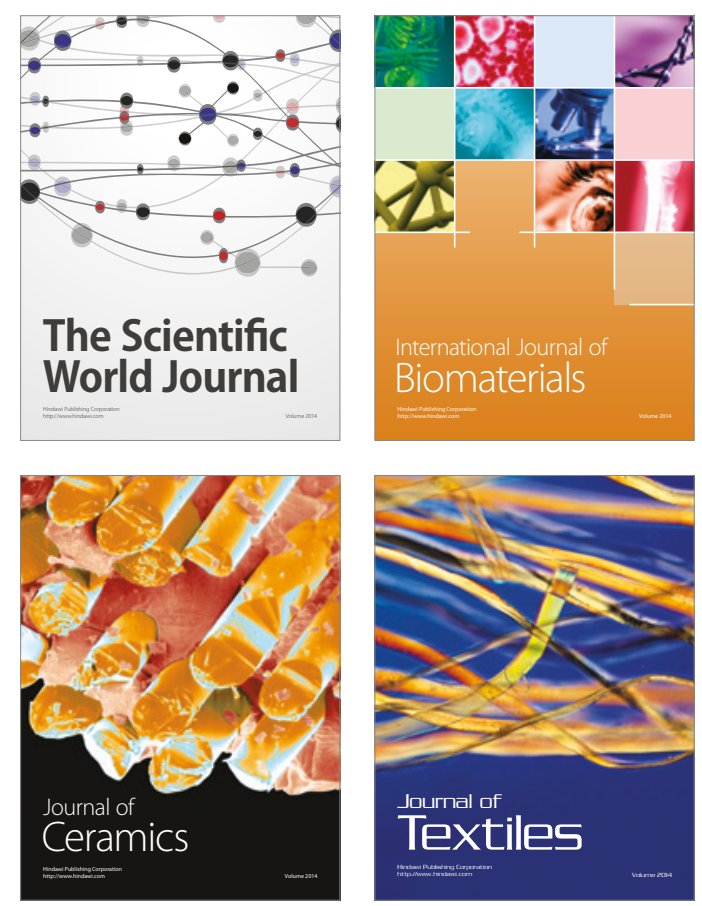